\title{
ПАРАМЕТРЫ АКТИВАЦИИ ЗОЛЫ УНОСА В КАЧЕСТВЕ ВЯЖУЩЕГО ПРИ ИЗГОТОВЛЕНИИ БЕТОНОВ
}

\author{
Голик Владимир Иванович ${ }^{1,2}$ \\ v.i.golik@mail.ru
}

\author{
Дмитрак Юрий Витальевич',
} dmitrak@yandex.ru

\author{
Качурин Николай Михайлович', \\ ecology_tsu_tula@mail.ru \\ Стась Галина Викторовна, \\ galina_stas@mail.ru \\ 1 Северо-Кавказский государственный технологический университет, \\ Россия, 362021, г. Владикавказ, ул. Николаева, 44. \\ 2 Геофизический институт Владикавказского научного центра, \\ Россия, 362002, г. Владикавказ, ул. Маркова, 93а. \\ 3 Тульский государственный университет, \\ Россия, 300012, г. Тула, пр. Ленина, 92.
}

\begin{abstract}
Актуальность исследования объясняется тем, что увеличение объемов использования товарного цемента при изготовлении бетонов, в том числе закладочных смесей для горного производства, сопровождается увеличением темпов добычи сырья для его изготовления и выбросов пылегазовых загрязнителей в атмосферу. Изыскиваются возможности замены его отходами смежных отраслей, например золой уноса от сжигания угля на тепловых электростанциях.

Целью исследования является доказательство того, что альтернативные источники вяжущих компонентов могут конкурировать с товарным цементом по основным показателям качества, будучи уже произведенными и наносящими ущерб в процессе хранения без утилизации.

Основным методом исследования является промышленный и лабораторный эксперимент с моделированием вяжущих свойств добавки к цементу. Полученные показатели систематизируются, интерпретируются графически и являются основанием для принятия решений.

Результаты. Доказана возможность и целесообразность частичной замены товарного цемента золой уноса от сжигания угля на тепловых электростанциях при соответствующей подготовке в активаторах-дезинтеграторах. Экспериментально определены количественные значения зависимости между расходом комплексного вяжущего и прочностью бетонной смеси, что позволяет скорректировать расход цемента при сохранении нужного качества бетона. Детализирована роль операции перемешивания для набора прочности смеси путем сравнения возможных способов перемешивания вручную и в дезинтеграторах. Установлен диапазон целесообразности режимов подготовки добавки к цементу.

Выводы. Добавка золы уноса при совместной активации с цементом может применяться в качестве вяжущего для изготовления бетонов в определенных диапазонах режимов подготовки, которые должны корректироваться для местных условий.
\end{abstract}

\section{Ключевые слова:}

Вяжущая компонента, зола уноса, дезинтегратор, цемент, бетон, экология.

\section{Введение}

Портландцемент в качестве вяжущего компонента, обладая универсальными технологическими и эксплуатационными свойствами, находит широкое применение практически во всех отраслях хозяйства $[1,2]$.

Однако, кроме дороговизны и дефицитности, производство цементов сопряжено с причинением экологического ущерба окружающей среде путем выбросов в атмосферу большого объема углекислого газа. Поэтому цемент пытаются заменять композитными минеральными добавками, из которых наиболее распространены доменные гранулированные шлаки, электро-термо-фосфорные шлаки, белитовые шламы и зола уноса, вводя их в состав цементов при совместном помоле с клинкером.
К наиболее распространенным промышленным отходам, пригодным для использования в качестве добавки, относится образующаяся при сжигании угля на тепловых электростанциях зола уноса (рис. 1).

Зола уноса составляет около $90 \%$ угольной золы, из которых не более 40 \% находит применение в различных отраслях, до $20 \%$ используется при производстве бетона и только небольшая часть находит применение в производстве вяжущих.

Достоинства золы уноса в качестве добавки [3-5]: - снижение расхода воды с обеспечением подвижности смеси;

- облегчение процесса укладки бетонной смеси;

- уменьшить тепловыделения и усадки бетона;

- уменьшение опасности трещинообразования. 
Введение золы уноса замедляет сроки схватывания, что объясняется медленной скоростью гидратации.

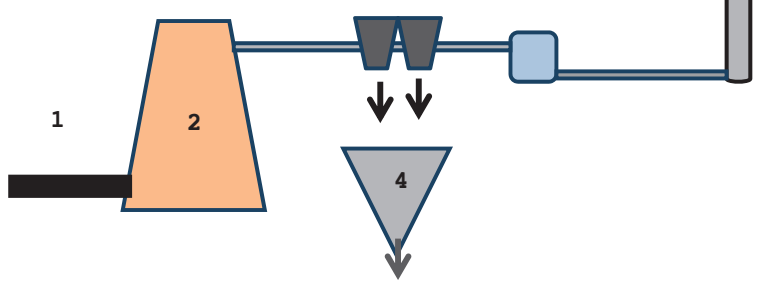

Рис. 1. Схема образования золы уноса: 1 - уголь; 2 - котел; 3 фильтр; 4 - бункер; 5-газы

Fig. 1. Scheme for fly ash formation: 1 is the coal; 2 is the boiler; 3 is the filter; 4 is the bunker; 5 are the gases

Бетоны с золой уноса характеризуются низким водоотделением, меньшей сегрегацией частиц, плотностью и весом бетона. Введение золы уноса в состав бетона снижает развитие усадочных деформаций при твердении.

Состав и структура золы уноса зависят от свойств сжигаемого топлива и особенностей его сгорания. Применение золы уноса как побочного материала позволяет существенно сократить затраты на сырье в процессе производства разного вида бетонов.

Область применения золы уноса:

- в составе тяжелых бетонов для монолитных конструкций как заменитель части песка или части цемента, или как активный улучшающий свойства бетона микро-наполнитель;

- в производстве стеновых блоков и строительстве для повышения агрегативной устойчивости смеси и формирования нужной структуры бетона.

Подавляющее большинство работающих на углях ТЭС и ТЭЦ не оборудованы фильтрами для улавливания пыли, и зола вместе со шлаками направляется в шламонакопители, что не позволяет эффективно утилизировать ее в производстве бетонов.

В состав золы ТЭЦ входят, \%: $\mathrm{SiO}_{2}-34-75$, $\mathrm{Al}_{2} \mathrm{O}_{3}-2-34, \mathrm{Fe}_{2} \mathrm{O}_{3}-1,5-18,5, \mathrm{CaO}-2-14,5$ и другие соединения [6-8].

Использование промышленных отходов горения угля относится к 90-м гг. прошлого века. Так, в Скандинавских странах уровень утилизации золы ТЭЦ доходит до 100 \% . В Европейскую ассоциацию по утилизации продуктов горения угля входят 15 стран, выпускающих 90 \% золошлаковых материалов.

Препятствием для расширения области использования зол уноса является наличие в них, как и других хвостах переработки, металлосодержащего сырья редкоземельных и других металлов. Поэтому утилизацию зол целесообразно начинать с из- влечения металлов, что пока еще является непреодолимым препятствием для утилизации золошлаковых отходов. Зола является практически заменителем бокситов.

Схема выщелачивания редкоземельных металлов из золошлаковых отходов включает в себя предварительную подготовку золошлаков, химическое выщелачивание, а также концентрирование редкоземельных металлов в растворе (рис. 2).

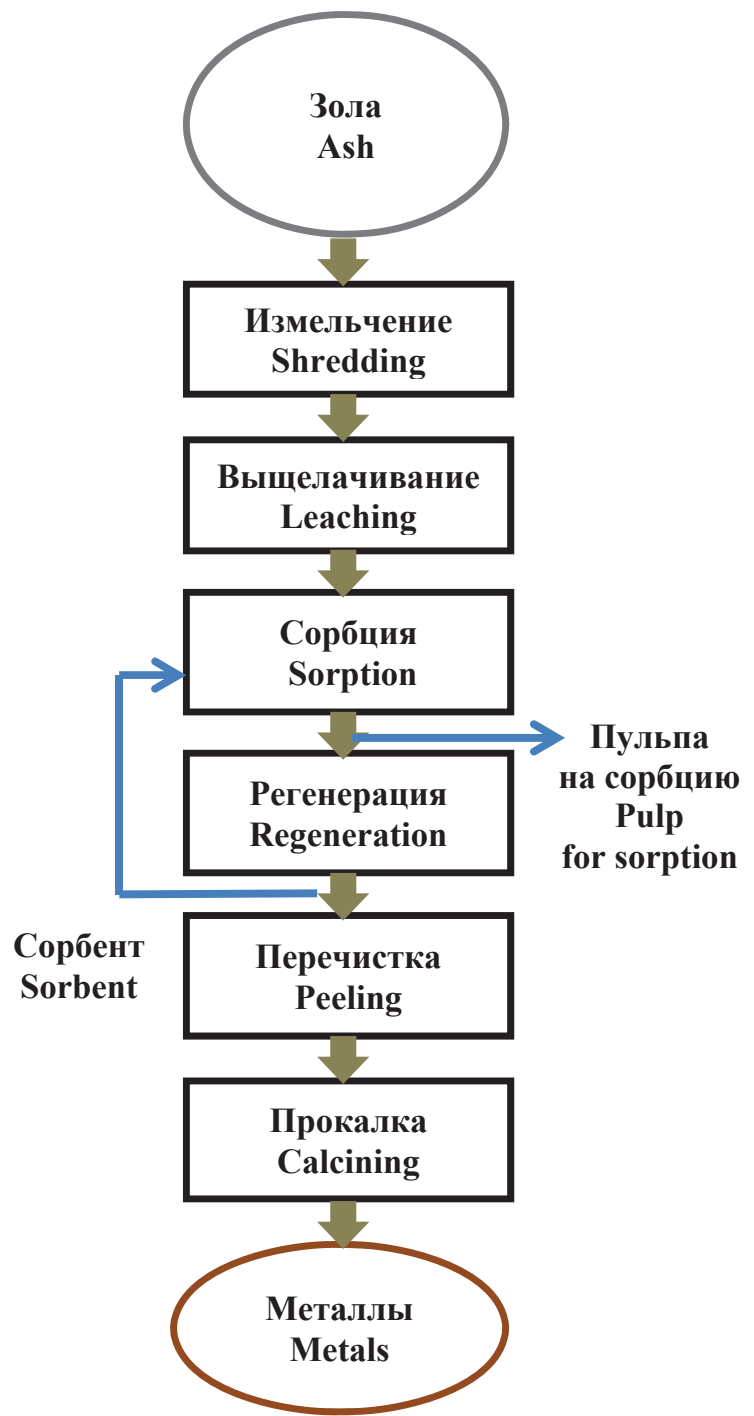

Рис.2. Схема выщелачивания металлов

Fig. 2. Metal leaching scheme

Предварительная подготовка золошлаковых отходов включает измельчение и усреднение зол по диаметру частиц. Выщелачивание включает контакт измельченной золы с водными растворами кислот. В дальнейшем используют сорбенты для извлечения металлов из коллективного раствора. Недостатком схемы является продолжительность и неполное извлечение металлов.

Дезинтегратор-активатор выполняет операции выщелачивания на два порядка быстрее и с полным извлечением металлов. Запрессовывание 
жидких реагентов в поры минералов осуществляется в рабочем органе дезинтегратора во время активации со скоростью более $250 \mathrm{~m} / \mathrm{c}$.

В России сухую золу перерабатывают практически полностью (10 \% ). В Омске на ТЭЦ-4 линия по отбору золы уноса обеспечивала сырьем два строительных завода. Золошлаки добавляют в цементы и в клинкер. На их основе делают зольные блоки, смешивая золу с цементом. Но в большинстве случаев золу используют для отсыпки основания дорог и заполнения пазух в строительстве.

Хорошими гидравлическими свойствами обладают золы с показателями 0,9-1,2. Твердеющая смесь с добавкой такой золы обладает прочностью до 8,0 МПа и пластичностью 80-100 Па.

При одинаковом расходе цемента прочность закладки с увеличением добавки золы возрастает.

Результаты использования зол уноса на ряде горных предприятий сводятся к следующему [9, 10]:

- зола уноса, полученная от сжигания углей Канско-Ачинского бассейна, обладает вяжущими свойствами без добавления цемента;

- затворение твердеющих смесей $3 \%$ растворами $\mathrm{HCl}$ и $\mathrm{CaCl}_{2}$ увеличивает прочность смесей и ускоряет сроки схватывания;

- зола ирша-бородинских углей менее активна, чем зола «Зв», но более активна, чем зола харанорских углей.

Для получения составов с прочностью 3,0-3,5 МПа необходим расход цемента 20-30 кгм ${ }^{3}$ вместо 100-120 кгм при использовании золы харанорских углей и 220-240 кгм без добавки золы. Такую же прочность твердеющих смесей с применением в качестве добавок мокро-молотого доменного гранулированного карагандинского шлака можно достигнуть при большем расходе цемента -50 кгм $^{3}$.

При добавке ирша-бородинской золы экономится около 200 кг цемента на $1 \mathrm{~m}^{3}$ закладки.

Зола канско-ачинских углей с Новосибирской ТЭЦ-3 может заменить карагандинские шлаки, сократив при этом расход цемента на 10-20 кгм При замене цементных вяжущих на зольно-цементные с Гусиноозерской ТЭЦ расход цемента снижается до 0-40 кгм ${ }^{3}$.

Лучшими качествами обладает зола от сжигания бурых углей Канско-Ачинского угольного бассейна, которая представляет собой практически готовое к употреблению вяжущее. Состав вяжущих ингредиентов по массе представлен в табл. 1.

Таблица 1. Состав вяжущих ингредиентов

Table 1. Composition of astringent ingredients

\begin{tabular}{|l|c|c|c|c|c|c|}
\hline \multirow{2}{*}{\multicolumn{1}{|c|}{$\begin{array}{c}\text { Наименование } \\
\text { Name }\end{array}$}} & \multicolumn{5}{|c|}{$\begin{array}{c}\text { Химический состав } \\
\text { Chemical composition, \% }\end{array}$} \\
\cline { 2 - 7 } & $\mathrm{SiO}_{2}$ & $\mathrm{Al}_{2} \mathrm{O}_{3}$ & $\mathrm{Fe}_{2} \mathrm{O}_{3}$ & $\mathrm{Ca0}$ & $\mathrm{MgO}$ & $\mathrm{SiO}_{3}$ \\
\hline $\begin{array}{l}\text { Зола бурых углей Канско- } \\
\text { Ачинского угольного бассейна } \\
\begin{array}{l}\text { Ash of brown coal of the } \\
\text { Kansk-Achinsk coal basin }\end{array}\end{array}$ & $20-40$ & $8-11$ & $10-15$ & $25-50$ & $2-4$ & $1-3$ \\
\hline $\begin{array}{l}\text { Портландцемент марки 500 } \\
\text { Portland cement brand 500 }\end{array}$ & $8-26$ & $4-9$ & $0,3-6$ & $62-68$ & $\geq 5$ & $1-3,5$ \\
\hline
\end{tabular}

Нами исследовано влияние количества добавок к цементу в комплексных вяжущих различного типа на прочность твердеющих смесей при использовании золы уноса от сжигания углей. Целью исследования было определить зависимость между расходом цемента с добавками золы уноса и прочностью бетона при различных параметрах подготовки, в частности скорости перемешивания компонентов бетонных смесей [11-16].

Экспериментальные смеси включали в себя портландцемент, золу уноса, хвосты обогатительного передела и воду.

Эксперимент включал в себя три этапа.

На первом этапе золу-унос совместно с цементом активировали в дезинтеграторе УДА-10 с интенсивным перемешиванием со скоростью вращения роторов 3000 об/мин или суммарной линейной скоростью - 46,5 м/с (рис. 3 ).

1

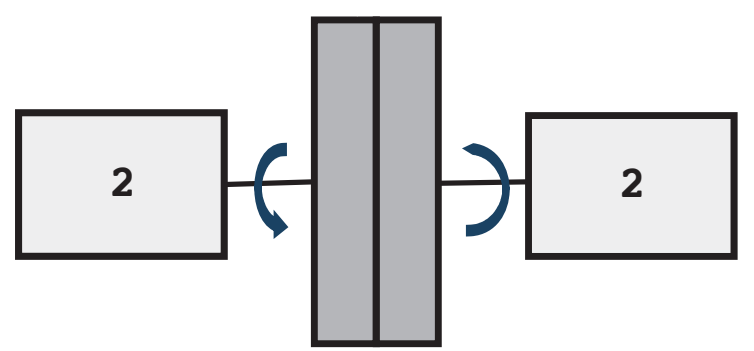

Pис.3. Схема дезинтегратора:1 - рабочая корзина с роторами; 2 - электродвигатели

Fig. 3. Disintegrator diagram: 1 is the working basket with rotors; 2 are the electric motors

При обработке в дезинтеграторе-активаторе частицы вяжущих получают быстро следующие друг за другом удары со скоростью удара более $250 \mathrm{M} / \mathrm{c}$, что изменяет их технологические свойства.

Конструкция дезинтегратора включает в себя вращающиеся в противоположные стороны ротоpa, насаженные на соосные валы. Материал подаётся в рабочий орган и, перемещаясь к периферии, подвергается ударам вращающихся с частотой 500-1000 об/мин пальцев.

Активация гранулированных шлаков металлургии в дезинтеграторе открывает перспективы получения вяжущих аналогов цемента и сокращает стоимость продуктов горного производства. Проблема утилизации отходов горного производства перспективна в социально-экономическом плане, поскольку опасные в настоящее время хвосты переработки становятся сырьевым источником для решения вопросов выживания горных предприятий. Большая часть потребностей производства в минеральном сырье может быть удовлетворена использованием уже накопленных хвостов переработки минералов. Эффективность утилизации минеральных отходов складывается из стоимости полученных товаров, сырья для строительной индустрии и снижения величины ущер- 
ба окружающей среде от хранения хвостов переработки.

Для дальнейших исследований была отобрана зола Канско-Ачинского бассейна. Результаты этапа сведены в табл. 2.

Таблица 2. Параметры твердеющей слеси с интенсивным пере мешиванием

Table 2. $\quad$ Parameters of hardening mixture with intensive mixing

\begin{tabular}{|c|c|c|c|c|c|c|}
\hline \multicolumn{4}{|c|}{ 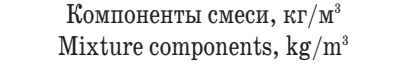 } & \multirow{2}{*}{\multicolumn{3}{|c|}{$\begin{array}{c}\text { Прочность, МПа } \\
\text { Strength, MPa } \\
\text { Возраст, c/Age, s }\end{array}$}} \\
\hline Цемент & Зола & Хвосты & Вода & & & \\
\hline Cement & Ash & Tails & Water & 7 & 14 & 28 \\
\hline 170 & - & 1242 & 435 & 0,4 & 1,2 & 1,3 \\
\hline 160 & 100 & 1093 & 490 & 1.0 & 1,6 & 2,0 \\
\hline 160 & 200 & 944 & 495 & 1,4 & 2,6 & 3,5 \\
\hline 160 & 300 & 796 & 500 & 2,2 & 3,6 & 5,3 \\
\hline 150 & 200 & 966 & 490 & 1,2 & 1,9 & 2,9 \\
\hline 150 & 300 & 818 & 495 & 1.6 & 2,4 & 4,0 \\
\hline 150 & 400 & 669 & 500 & 1,9 & 3,5 & 5,2 \\
\hline 150 & 500 & 520 & 505 & 2,5 & 4,1 & 6,5 \\
\hline
\end{tabular}

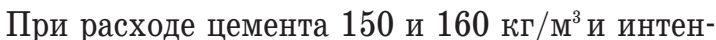
сивном перемешивании прочность смеси с увеличением количества золы уноса возрастает. Прочность смеси с добавкой золы в разы превышает исходную прочность без добавки цемента.

Образцы второго этапа исследования изготовили при тех же условиях, но компоненты смеси смешивали вручную. Прочность смеси оказалась в разы меньше, чем при интенсивном перемешивании, но при увеличении расхода золы также увеличилась (табл. 3).

Таблица 3. Прочность твердеющей слеси с перемешиванием вручную

Table 3. $\quad$ Strength of the hardening mixture with manual mixing

\begin{tabular}{|c|c|c|c|c|c|c|}
\hline \multicolumn{4}{|c|}{$\begin{array}{c}\text { Компоненты смеси, } \mathrm{kг} / \mathrm{m}^{3} \\
\text { Components of the mixture, } \mathrm{kg} / \mathrm{m}^{3}\end{array}$} & \multirow{2}{*}{\multicolumn{3}{|c|}{$\begin{array}{c}\text { Прочность, МПа } \\
\text { Strength, MPa } \\
\text { Возраст, с/Age, s }\end{array}$}} \\
\hline \multirow{2}{*}{$\begin{array}{l}\text { Цемент } \\
\text { Cement }\end{array}$} & \multirow{2}{*}{$\begin{array}{c}\text { Зола } \\
\text { Ash }\end{array}$} & \multirow{2}{*}{$\begin{array}{l}\text { Хвосты } \\
\text { Tails }\end{array}$} & \multirow{2}{*}{$\begin{array}{c}\text { Вода } \\
\text { Water }\end{array}$} & & & \\
\hline & & & & 7 & 14 & 28 \\
\hline 160 & 300 & 822 & 490 & 0,63 & 0,99 & 2,1 \\
\hline 140 & 300 & 640 & 490 & 0,56 & 0,37 & 1,9 \\
\hline 120 & 300 & 857 & 490 & 0,39 & 0,71 & 1,6 \\
\hline 100 & 300 & 874 & 490 & 0,27 & 0,60 & 1,3 \\
\hline 140 & 400 & 704 & 490 & 0,59 & 1,0 & 2,1 \\
\hline 120 & 400 & 722 & 490 & 0,45 & 0,82 & 1,8 \\
\hline 100 & 400 & 739 & 490 & 0,32 & 0,69 & 1,4 \\
\hline 120 & 500 & 586 & 490 & 0,51 & 0,93 & 2,0 \\
\hline 100 & 500 & 604 & 490 & 0,38 & 0,82 & 1,7 \\
\hline
\end{tabular}

Так, в возрасте 28 дней добавка 200 кг/м³ золы

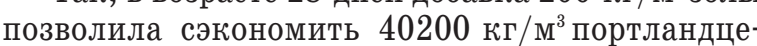
мента.

На третьем этапе эксперимента компоненты твердеющей смеси перемешивали вручную, а затем провели ее обработку при помощи лопастной быстроходной мешалки при режиме 3500 об/мин в течение трех минут (табл. 4).

Состав твердеющей смеси (на $\left.\mathrm{m}^{3}\right)$ : цемент M 400 - 120 кг; зола уноса Рефтинской ГРЭС 300 кг; хвосты обогащения - 357 кг; вода -490 л.
Таблииа 4. Прочность твердеющей смеси с перемешиванием вручную и активацией

Table 4. Hardening mixture strength at manual mixing and activation

\begin{tabular}{|c|c|c|c|c|c|}
\hline \multirow{3}{*}{$\begin{array}{c}\text { Линейная } \\
\text { встречная ско- } \\
\text { рость, м/с } \\
\text { Linear counter } \\
\text { speed, m/s }\end{array}$} & \multirow{3}{*}{$\begin{array}{c}\text { Предельное } \\
\text { напряжение } \\
\text { сдвига, Па } \\
\text { Ultimate shear } \\
\text { stress, Pa }\end{array}$} & \multirow{3}{*}{$\begin{array}{c}\text { Коэффициент } \\
\text { отстоя воды, \% } \\
\text { Water } \\
\text { sedimentation } \\
\text { coefficient, \% }\end{array}$} & \multirow{2}{*}{\multicolumn{3}{|c|}{$\begin{array}{l}\text { Прочность, МПа } \\
\text { Strength, MPa } \\
\text { Bозраст, c/Age, s }\end{array}$}} \\
\hline & & & & & \\
\hline & & & 7 & 14 & 28 \\
\hline 30 & 123 & 90,3 & 0,50 & 1,8 & 3,4 \\
\hline 40 & 117 & 91,2 & 0,52 & 1,9 & 2,7 \\
\hline 50 & 110 & 90,3 & 0,56 & 1,4 & 2,5 \\
\hline 60 & 107 & 88,7 & 0,53 & 1.1 & 2,4 \\
\hline 80 & 105 & 89,3 & 0,48 & 1,1 & 2,7 \\
\hline 100 & 108 & 90,6 & 0,50 & 1,5 & 3,9 \\
\hline
\end{tabular}

Максимальная скорость обработки 30-40 м/с (перемешивание) и $100 \mathrm{~m} / \mathrm{c}$ (измельчение).

Прочность образцов, изготовленных при скоростях 30-40 м/с (табл. 3) и при перемешивании вручную (табл. 2), приведена в табл. 5 .

Таблица 5. Прочность слеси при различных режилах перелеши вания компонентов

Table 5. Mixture strength at different modes of mixing components

\begin{tabular}{|c|c|c|c|c|c|}
\hline \multirow{3}{*}{$\begin{array}{c}\text { Линейная } \\
\text { встречная } \\
\text { скорость, м/с } \\
\text { Linear counter } \\
\text { speed, m/s }\end{array}$} & \multirow{3}{*}{$\begin{array}{c}\text { Предельное } \\
\text { напряжение } \\
\text { сдвига, Па } \\
\text { Ultimate shear } \\
\text { stress, Pa }\end{array}$} & \multirow{3}{*}{$\begin{array}{c}\text { Коэффициент } \\
\text { отстоя воды, \% } \\
\text { Water sedimenta- } \\
\text { tion coefficient, } \\
\text { \% }\end{array}$} & \multirow{2}{*}{\multicolumn{3}{|c|}{$\begin{array}{c}\text { Прочность } \\
\text { смеси, МПа } \\
\text { Strength, MPa } \\
\text { Bозраст, c/Age, s }\end{array}$}} \\
\hline & & & & & \\
\hline & & & 7 & 14 & 28 \\
\hline 30 & 423 & 90,3 & 0,5 & 1,8 & 3,4 \\
\hline 40 & 117 & 91,2 & 0,52 & 1,9 & 2,7 \\
\hline- & 121 & 95,2 & 0,39 & 0,71 & 1,6 \\
\hline
\end{tabular}

Определено, что при интенсивном перемешивании в дезинтеграторе прочность бетонной смеси увеличивается в $1,5-2$ раза и более. Оптимальной для перемешивания смеси цемента и золы уноса является скорость 30-40 м/с. Дальнейшее увеличение скорости нецелесообразно.

Результаты исследования хорошо согласуются с выводами Российских и зарубежных специалистов [17-20].

\section{Выводы}

1. Возможность частичной замены цемента золой уноса от сжигания угля на тепловых электростанциях подтверждается экспериментально и должна корректироваться в конкретных условиях.

2. Вовлечение в производство альтернативных вяжущих позволяет увеличить сырьевую базу приготовления цемента и уменьшить ущерб окружающей среде.

3. Экспериментально определенные зависимости между расходом комплексного вяжущего и прочностью бетонной смеси позволяют скорректировать расход цемента при сохранении качества бетона.

4. Добавка золы уноса целесообразна для изготовления бетонов в определенных диапазонах режимов подготовки. 


\section{СПИСОК ЛИТЕРАТУРЫ}

1. Der Braunkohlentagebau Bedeutung, Planung, Betrieb, Technik, Umwelt / R.D. Stoll, Ch. Niemann-Delius, C. Drebenstedt, K. Müllensiefen. - Berlin: Springer-Verlag, 2009. - 605 p.

2. Анализ перспективности применения золы-уноса в технологии геополимеров / М.О. Коровкин, В.М. Володин, Н.А. Ерошкина, М.Ю. Чамурлиев, И.Ю. Лавров // Молодежный научный вестник. - 2017. - № 10 (23). - С. 70-77.

3. Bowman S.D. Interferometric Synthetic Aperture Radar (InSAR) // Background and Application: guidelines for investigating geologic hazards and preparing engineering geology reports, with a suggested approach to geologic-hazard ordinances in Utah. Utah: The University of Utah, 2016. - P. 198-203.

4. The history of Russian Caucasus ore deposit development / V.I. Golik, Yu.I. Razorenov, V.N. Ignatov, Z.M. Khasheva // The Social Sciences (Pakistan). - 2016. - V. 11. - № 15. P. $3742-3746$.

5. Дмитрак Ю.В., Камнев Е.Н. А0 «Ведущий проектно-изыскательский и научно-исследовательский институт промышленной технологии» Путь длиной в 65 лет // Горный журнал. 2016. - № 3. - C. $6-12$.

6. Chen H.L. Brief analysis of the technical points about the tailings pond environmental impact assessment // Advanced Materials Research. - 2014. - V. 955-959. - P. 1685-1689.

7. Shaikh F.U.A., Supit S.W.M. Mechanical and durability properties of high volume fly ash (HVFA) concrete containing calcium carbonate $\left(\mathrm{CaCO}_{3}\right)$ nanoparticles // Construction and Building Materials. - 2014. - V. 70. -P. 309-321.

8. Комащенко В.И. Эколого-экономическая целесообразность утилизации горнопромышленных отходов с целью их переработки // Известия Тульского государственного университета. Науки $о$ Земле. - 2015. - № 4. - С. 23-30.

9. High-volume fly ash concrete with and without hydrated lime: chloride diffusion coefficient from accelerated test / J.H. Filho, M.H.F. Medeiros, E. Pereira et al. // Journal of Materials in Civil Engineering. - 2013. - V. 25. - Iss. 3. - P. 411-418.

10. The effectiveness of combining the stages of ore fields development / V. Golik, V. Komaschenko, V. Morkun, Z. Khasheva // Metallurgical and Mining Industry. - 2015. -V. 7. - № 5. P. 401-405.

11. Голик В.И., Комащенко В.И., Качурин Н.М. Концепция комбинирования технологий разработки рудных месторождений //
Известия Тульского государственного университета. Науки 0 Земле. - 2015. - № 4. - С. 76-88.

12. Ляшенко В.И., Стусь В.П. Охрана окружающей среды в зоне влияния уранового производства // Безопасность жизнедеятельности. - 2015. - № 3. - С. 37-44.

13. Rashad A.M. Potential use of phosphogypsum in alkaliactivated fly ash under the effects of elevated temperatures and thermal shock cycles // Journal of Cleaner Production. - 2015. - V. 87. P. $717-725$.

14. Прокопов А.Ю., Масленников С.А., Шинкарь Д.И. 0 влиянии специфических условий строительства вертикальных стволов на формирование прочностных характеристик бетона // Научное обозрение. - 2013. - № 11. - С. 102-107.

15. Silva P., De Brito J. Electrical resistivity and capillarity of selfcompacting concrete with incorporation of fly ash and limestone filler // Advances in concrete construction. - 2013. - V. 1. Iss. 1. - P. 65-84.

16. Mining Impact on Environment on the North Ossetian Territory / 0.G. Burdzieva, V.B. Zaalishvili, O.G. Beriev, A.S. Kanukov, M.V. Maisuradze // International Journal of geomate. - 2016. V. 10. - № 1. - P. 1693-1697.

17. Новые технологии подземных сооружений в рамках сдержанных городских условий / М. Плешко, А. Панкратенко, А. Ревякин, Е. Щекина, С. Холодова // ES Web of Conferences. 2018. - V 33. -02036 .

18. Изыскание эффективной технологии утилизации отходов горно-обогатительного производства в составе твердеющих закладочных смесей / М.В. Рыльникова, Д.Н. Радченко, В.В. Григорьев, К.Ж. Рахматуллина // Недропользование: XXI век. 2009. - № 3. - C. 33-37.

19. Morkun V., Morkun N., Tron V. Identification of control systems for ore-processing industry aggregates based on nonparametric kernel estimators // Metallurgical and Mining Industry. 2015. - № 1. - P. 14-17.

20. Разработка технологии закладочных работ на основе цементно-шлакового вяжущего на Орловском руднике / Л.А. Крупник, Ю.Н. Шапошник, С.Н. Шапошник, Г.Т. Нуршайыкова, 3.К. Тунгушбаева // Физико-технические проблемы разработки месторождений полезных ископаемых. - 2017. - № 1. C. $58-64$.

Поступила 31.05.2019 2.

\section{Информация об авторах}

Голик В.И., доктор технических наук, профессор, профессор кафедры горного дела Северо-Кавказского государственного технологического университета; главный научный сотрудник Геофизического института Владикавказского научного центра.

Длитрак Ю.В., доктор технических наук, профессор, ректор Северо-Кавказского государственного технологического университета.

Качурин H.M., доктор технических наук, профессор, заведующий кафедрой геотехнологии и строительства подземных сооружений Тульского государственного университета.

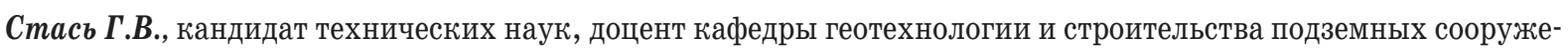
ний Тульского государственного университета. 
UDC 504.55.054: 622 (470.6)

\title{
PARAMETERS OF ASH DRAIN ACTIVATION AS A BINDER WHEN MAKING A CONCRETE
}

\author{
Vladimir I. Golik', \\ v.i.golik@mail.ru \\ Yury V. Dmitrak', \\ dmitrak@yandex.ru \\ Nikolay M. Kachurin ${ }^{3}$, \\ ecology_tsu_tula@mail.ru

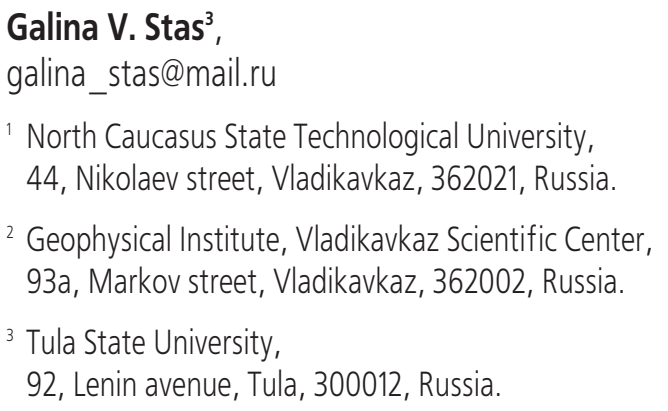

The relevance of the study is explained by the fact that increase in using commodity cement in manufacture of concrete, including filling mixes for mining, is accompanied by growth in production rate of raw materials for its production and emission of dust-gas pollutants into the atmosphere. One try to find the ways of replacing it by waste from related industries, such as fly ash from coal combustion in thermal power plants.

The aim of the study is to prove that alternative sources of binding components can compete with commercial cement in basic quality indicators, already produced and damaging during storage without recycling.

The main research method is an industrial and laboratory experiment with modeling the cementitious binders. The obtained indicators are systematized, interpreted graphically and they are the basis for decision-making.

Results. The authors have proved the possibility and expediency of partial replacement of marketable cement by fly ash from coal combustion in thermal power plants with appropriate training in activators-disintegrators. The quantitative values of relationship between complex binder consumption and concrete mix strength are experimentally determined, which makes it possible to correct cement consumption while maintaining the desired quality of concrete. The role of mixing operation was detailed to improve the strength of the mixture by comparing possible methods of mixing manually and in disintegrators. The range of expediency of preparing additives for cement was established.

Findings. The addition of fly ash at joint activation with cement can be used as a binder for manufacturing concrete in certain ranges of preparation modes.

\section{Key words:}

Binder component, fly ash, disintegrator, cement, concrete, ecology.

\section{REFERENCES}

1. Stoll R.D., Niemann-Delius Ch., Drebenstedt C., Müllensiefen K. Der Braunkohlentagebau Bedeutung, Planung, Betrieb, Technik, Umwelt [Lignite mining. Meaning, planning, operation, technology, environment]. Berlin, Springer-Verlag, 2009. 605 p.

2. Korovkin M.O., Volodin V.M., Eroshkina N.A., Chamurliev M.Yu., Lavrov I.Yu. Analysis of the prospects of the use of fly ash in the technology of geopolymers. Molodezhny nauchny vest nik, 2017, no. 10 (23), pp. 70-77. In Rus.

3. Bowman S.D. Interferometric Synthetic Aperture Radar (InSAR). Background and Application: guidelines for investigating geologic hazards and preparing engineering geology reports, with a suggested approach to geologic-hazard ordinances in Utah. Utah, The University of Utah, 2016. pp. 198-203.

4. Golik V.I., Razorenov Yu.I., Ignatov V.N., Khasheva Z.M. The history of Russian Caucasus ore deposit development. The Social Sciences (Pakistan), 2016, vol. 11, no. 15, pp. 3742-3746.

5. Dmitrak Yu.V., Kamnev E.N. A0 «Leading design and survey and research institute of industrial technology» The path length of 65 years. Gorny zhurnal, 2016, no. 3, pp. 6-12. In Rus.
6. Chen H.L. Brief analysis of the technical points about the tailings pond environmental impact assessment. Advanced Materials Research, 2014, vol. 955-959, pp. 1685-1689.

7. Shaikh F.U.A., Supit S.W.M. Mechanical and durability properties of high volume fly ash (HVFA) concrete containing calcium carbonate $\left(\mathrm{CaCO}_{3}\right)$ nanoparticles. Construction and Building $\mathrm{Ma}$ terials, 2014, vol. 70, pp. 309-321.

8. Komashchenko V.I. Ecological and economic feasibility of disposal of mining waste for the purpose of their processing. Izvestiya Tulskogo gosudarstvennogo universiteta. Nauki o Zemle, 2015, no. 4, pp. 23-30. In Rus.

9. Filho J.H., Medeiros M.H.F., Pereira E. High-volume fly ash concrete with and without hydrated lime: chloride diffusion coefficient from accelerated test. Journal of Materials in Civil Engineering, 2013, vol. 25, Iss. 3, pp. 411-418.

10. Golik V., Komaschenko V., Morkun V., Khasheva Z. The effectiveness of combining the stages of ore fields development. Metallurgical and Mining Industry, 2015, vol. 7, no. 5, pp. 401-405.

11. Golik V.I., Komashchenko V.I., Kachurin N.M. The concept of combining technology for the development of ore deposits. Izves- 
tiya Tulskogo gosudarstvennogo universiteta. Nauki o Zemle, 2015, no. 4, pp. 76-88. In Rus.

12. Lyashenko V.I., Stus V.P. Environmental protection in the zone of influence of uranium production. Bezopasnost zhiznedeyatelnosti, 2015, no. 3, pp. 37-44. In Rus.

13. Rashad A.M. Potential use of phosphogypsum in alkali activated fly ash under the effects of elevated temperatures and thermal shock cycles. Journal of Cleaner Production, 2015, vol. 87, pp. $717-725$.

14. Prokopov A.Yu., Maslennikov S.A., Shinkar D.I. On the influence of specific conditions for the construction of vertical shafts on the formation of the strength characteristics of concrete. Nauchnoe obozrenie, 2013, no. 11, pp. 102-107. In Rus.

15. Silva P., De Brito J. Electrical resistivity and capillarity of selfcompacting concrete with incorporation of fly ash and limestone filler. Advances in concrete construction, 2013, vol. 1, Iss. 1, pp. $65-84$.

16. Burdzieva 0.G., Zaalishvili V.B., Beriev 0.G., Kanukov A.S., Maisuradze M.V. Mining impact on environment on the north 0ssetian territory. International Journal of geomate, 2016, vol. 10, no. 1, pp. 1693-1697.
17. Pleshko M., Pankratenko A., Revyakin A., Shchekina E., Holodova $\mathrm{S}$. New technologies of underground structures in a restrained urban environment. ES Web of Conferences, 2018, vol. 33, 02036. In Rus.

18. Rylnikova M.V., Radchenko D.N., Grigorev V.V., Rahmatullina K.Zh. Izyskanie effektivnoy tekhnologii utilizatsii otkhodov gorno-obogatitelnogo proizvodstva $v$ sostave tverdeyushchkih $z a$ kladochnykh smesey [Search for an effective technology for disposal of waste mining and processing production in composition of hardening filling mixtures]. Moscow, Nedropolzovanie: XXI vek Publ., 2009. No. 3, pp. 33-37.

19. Morkun V., Morkun N., Tron V. Identification of control systems for ore-processing industry aggregates based on nonparametric kernel estimators. Metallurgical and Mining Industry, 2015, no. 1, pp. 14-17.

20. Krupnik L.A., Shaposhnik Yu.N., Shaposhnik S.N., Nurshaykova G.T., Tungushbaeva Z.K. Development of technology of backfilling on the basis of cement-slag binder at Orlovsky mine. Fiziko-tekhnicheskie problemy razrabotki mestorozhdeniy poleznykh iskopaemykh, 2017, no. 1, pp. 58-64. In Rus.

Received: 31 May 2019.

\section{Information about the authors}

Vladimir I. Golik, Dr. Sc., professor, North Caucasus State Technological University; chief researcher, Geophysical Institute, Vladikavkaz Scientific Cente.

Yury V. Dmitrak, Dr. Sc., professor, rector, North Caucasus State Technological University.

Nikolay M. Kachurin, Dr. Sc., professor, head of the Department of Geotechnology and Underground Structures, Tula State University.

Galina V. Stas, Cand. Sc., associate professor, Tula State University. 